\title{
CEREBRAL ABSCESS CAUSED BY Serratia marcescens IN A PREMATURE NEONATE
}

\author{
Tatiana Mattos Hirooka', Ricardo Braganca de Vasconcellos Fontes², \\ Edna Maria Diniz', Fernando Campos Pinto², Hamilton Matushita ${ }^{2}$
}

\begin{abstract}
Background: Cerebral abscesses are extremely rare in neonates. Serratia marcescens is an unusual cause of sepsis and neurological spread is especially ominous. Purpose: To report the case of a 34-week neonate who developed this rare condition and to discuss diagnostic and therapeutic measures. Case report: A 34-week male neonate sequentially developed respiratory distress syndrome, early sepsis and necrotizing enterocolitis; later cultures revealed S. marcescens. After deterioration, a cerebral abscess became evident, which revealed S. marcescens. Clinical improvement ensued after high-dose amikacin and meropenem. Conclusion: Clinical signs are often non-specific. Proper diagnostic measures, neurosurgical consultation and aggressive antibiotic therapy are essential for these high-risk neonates.
\end{abstract}

KEY WORDS: brain abscess, infant, premature, intensive care, neonatal, meningoencephalitis, Serratia marcescens.

\begin{abstract}
Abscesso cerebral causado por Serratia marcescens em prematuro
RESUMO - Introdução: Abscessos cerebrais são extremamente raros em neonatos. Serratia marcescens é causadora incomum de sepse nestes pacientes e a disseminação no sistema nervoso central é grave. Objetivo: Relatar um prematuro de 34 semanas que desenvolveu esta condição e discutir as medidas diagnósticas e terapêuticas. Relato de caso: Prematuro masculino de 34 semanas desenvolveu síndrome do desconforto respiratório, sepse neonatal e enterocolite necrotizante; hemoculturas revelaram S. marcescens. Após deterioração clínica, evidenciou-se um abscesso cerebral cuja drenagem revelou S. marcescens. Houve melhora após introdução de amicacina e meropenem. Conclusão: Os sinais clínicos são inespecíficos. Passos diagnósticos apropriados, avaliação neurocirúrgica precoce e antibioticoterapia agressiva são essenciais para estes prematuros.
\end{abstract}

PALAVRAS-CHAVE: abcesso cerebral, prematuro, recém-nascido, meningoencefalite, Serratia marcescens.

Cerebral abscesses are extremely rare in neonates and usually arise in the setting of sepsis in patients with several other morbid conditions. Clinical signs are usually non-specific, signaling towards a rapidly deteriorating infant; consequently, cerebral abscesses are frequently diagnosed only during autopsy. This condition is further aggravated when premature infants or non-usual pathogens are involved ${ }^{1-3}$.

Serratia marcescens has emerged in the 1980 os as a known cause of sepsis in neonatal intensive care units (NICU), frequently involving pre-term, low birth weight and other immunocompromised neonates. Even though still unusual, reports of Serratia outbreaks have become more frequent in the last 10 years and are particularly alarming, since septic patients have very high morbidity and mortality rates and thus led to a series of strict infection control measures in all centers affected ${ }^{3}$. Neurological spread involving the meninges or the parenchyma itself is especially feared since this patient subgroup frequently has a very poor neurological outcome ${ }^{2}$. In this setting, cerebral abscesses secondary to Serratia sepsis are extremely rare but further complicate an already dangerous condition. Its diagnosis and treatment may become formidable challenges for even the most experienced neonatologists.

Therefore our objective is to report a case of cerebral abscess caused by Serratia marcescens in our NICU and to perform a literature review including the clinical presentation, treatment and outcome of reported patients.

Faculdade de Medicina da Universidade de São Paulo, São Paulo SP, Brazil (FMUSP): 'Department of Pediatrics; ${ }^{2}$ Department of Neurology and Neurosurgery.

Received 27 February 2007, received in final form 8 June 2007. Accepted 8 August 2007.

Dr. Ricardo B.V. Fontes - Rua Jandiro J. Pereira 389 - 05658-00o São Paulo SP - Brasil. E-mail: rbvfontes@yahoo.com.br 


\section{CASE}

A male, first of two twins, was delivered by caesarean section at 34 weeks gestation with a weight of $1255 \mathrm{~g}$. This infant developed mild respiratory distress syndrome that quickly resolved on day 3. On this same day, thrombocytopenia and leucopenia became evident, which prompted the start of empiric antibiotic therapy (ampicillin and cefotaxime) in spite of normal blood and cerebrospinal fluid (CSF) cultures. A patent ductus arteriosus was also discovered on day 3 after echocardiogram examination.

Necrotizing enterocolitis was diagnosed on day 5; progressive clinical deterioration led to the introduction of vancomycin and cefotaxime on day 7. Disseminated intravascular coagulation ensued on day 17, and antibiotics were once again modified to vancomycin, meropenem and anfotericin B. Peritoneal dialysis was performed from day 19 to 23 due to acute renal failure, while thrombocytopenia also worsened, reaching 1000 platelets/ $\mu \mathrm{L}$ on day 22. At this point, Serratia marcescens was isolated from blood cultures. In vitro assays showed adequate sensibility to meropenem and antibiotics were not modified.

The first cerebral ultrasound (US) exam was also performed on day 22. A right parietal hemorrhagic focus was detected, measuring $3 \mathrm{~cm}$ in diameter. Clinical conditions gradually improved and computerized tomography (CT) revealed right parietal encephalomalacia. However, on day 34 the infant became febrile again; C-reactive protein and leucocyte counts also increased. CSF examination yielded 95 cells with elevated protein and low glucose ( $18 \mathrm{mg} / \mathrm{dL}$ ). Two days later several seizures were observed and a repeat CT scan was obtained. A large $(4 \mathrm{~cm})$ right temporo-parietal abscess with adjacent edema and ring enhancement after IV contrast was evident (Figure A). Neurosurgical consultation was immediately obtained and abscess drainage indicated. Twenty-six milliliters of pus were removed by needle

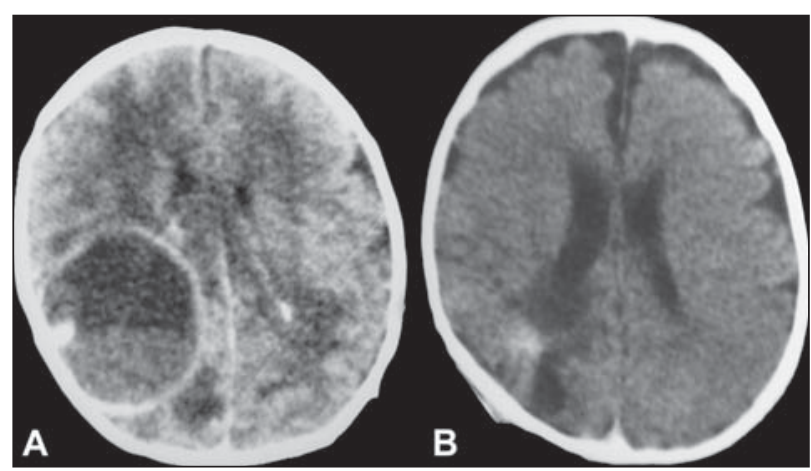

Figure. (A) Preoperative CT scan with IV contrast, day 36. Large temporo-parietal abscess with typical ring enhancement, adjoining edema and midline shift. (B) CT scan with IV contrast, day 120 (at discharge): only residual abscess capsule and encephalomalacia are visible.

aspiration; culture results of abscess fluid also revealed Serratia marcescens. Once again, in vitro assays revealed adequate coverage by meropenem and other antibiotics were suspended.

Clinical conditions once again improved while the abscess gradually diminished on repeat CT scans every 14 days. However, on day 60 , conditions worsened when fever, vomiting and seizures started, which after CT examination were considered to be secondary to abscess rupture into the subarachnoid space. No neurosurgical intervention was considered necessary but high-dose amikacin was added to meropenem. This time rapid improvement followed and the remaining clinical course was uneventful. Antibiotics were suspended after 42 days and the infant was discharged on day 120 with normal CT neurological development for age (Figure B). Appropriate informed consent was obtained before reporting this case.

Table. Cerebral abscess by S. marcescens: summary of reported cases.

\begin{tabular}{|c|c|c|c|c|c|c|c|}
\hline $\begin{array}{c}\text { Ref. } \\
\#\end{array}$ & $\begin{array}{l}\text { Patient } \\
\quad \#\end{array}$ & BW & GA & Clinical picture & Antibiotic therapy & Surgical procedure & Outcome \\
\hline \multirow[t]{3}{*}{2} & 3 & 804 & 25 & RDS, late sepsis & $\begin{array}{l}\text { Meropenem }(51 d)+ \\
\text { Amikacin }(10 d) / \\
\text { Fosfomycin }(15 d)\end{array}$ & None & Moderate sequelae \\
\hline & & 1261 & 32 & RDS, sepsis, seizures & Cefotaxime + Amikacin & VPS & Severe sequelae \\
\hline & & 646 & 28 & Sepsis & $\begin{array}{l}\text { Ciprofloxacin (21d) } \\
+ \text { Cefipime (35d) }\end{array}$ & None & Good \\
\hline 6 & 1 & 1240 & 31 & Sepsis & $\begin{array}{l}\text { Ceftazidime (56d) } \\
+ \text { Amikacin (14d) }\end{array}$ & None & Good \\
\hline \multirow[t]{2}{*}{5} & 2 & 1470 & 33 & Sepsis & $\begin{array}{l}\text { Cefotaxime }+ \\
\text { Tobramycin }\end{array}$ & $\begin{array}{l}\text { Abscess and external } \\
\text { CSF drainage, VPS }\end{array}$ & Moderate hypotonia \\
\hline & & 930 & 30 & $\begin{array}{l}\text { Sepsis, intraventricular } \\
\text { hemorrhage }\end{array}$ & NM & NM & Severe sequelae \\
\hline 7 & 1 & 1000 & NM & $\begin{array}{l}\text { Intracerebral } \\
\text { hemorrhage }\end{array}$ & $\begin{array}{l}\text { Cefoxitin (49d) + } \\
\text { Amikacin (19d) }\end{array}$ & $\begin{array}{l}\text { Abscess US-guided } \\
\text { drainage (twice) }\end{array}$ & Mild sequelae \\
\hline
\end{tabular}

Ref. \#, reference number; BW, birth weight (grams); GA, gestational age (weeks); d, days; CSF, cerebrospinal fluid; VPS, ventriculo-peritoneal shunt; RDS, respiratory distress syndrome; NM, not mentioned. 


\section{DISCUSSION}

Originally described in 1823 by Bizio, bacteria from the genus Serratia were initially considered non-pathogenic. Woodward and Clark reported the first case of human infection caused by Serratia marcescens in 1913 but it was not until 1943 that the first case of meningitis was described by Aronson and Alderman'. Progressively recognized as a cause of nosocomial infection, S. marcescens was from the $1960 \mathrm{~s}$ onward also considered a major threat for immunocompromised patients. Through a pioneer authopsy study in 1965, Ragazzini et al. described the pathologic findings of $S$. marcescens sepsis in neonates, including the first known case of meningoencephalitis. Initially considered a rare event, increased awareness for sepsis caused by S. marcescens in neonates led to more frequent identification and treatment of this bacteria; accordingly, several outbreaks in neonatal intensive care units have been reported since the 198 os $^{1-4}$.

Predisposing factors for S. marcescens sepsis include prematurity, necrotizing enterocolitis and persistent ductus arteriosus; all of them were present in our infant. These factors facilitate the passage of enteric Gram-negative bacteria into the bloodstream, thus initiating the septic process. Meningitis, though relatively infrequent, is a known complication of $S$. marcescens sepsis and increases its already high morbidity and mortality rates. Campbell et al. reported 38 cases of bacteremia or meningitis during a five-year period in their NICU; eleven of these neonates had meningitis with a $30 \%$ mortality rate, while Al-Harthi et al. reported the identification of S. marcescens in $\mathbf{2 1 \%}$ of their cases of neonatal meningitis, a rate far greater than other studies found in the literature ${ }^{3,4}$. Based on these and several other reports of S. marcescens outbreaks, meningitis alone can be recognized as an indicator of poor prognosis. The clinical picture and outcome of these patients may become even worse when bacterial meningitis progresses toward some of its known complications with direct involvement of the cerebral parenchyma or ventricles, such as meningoencephalitis, ventriculitis or cerebral abscesses ${ }^{2,3,5}$.

Cerebral abscesses secondary to S. marcescens infection are the most unusual of these complications with only 7 cases reported in the last 20 years (Table); the 3 cases from the University of Vienna have been reported twice, from both pediatric and radiological standpoints ${ }^{2,5-8}$. The only additional predisposing factor for cerebral seeding is intracerebral hemorrhage, which is thought to provide S. marcescens a site with disrupted blood-brain barrier and diminished immune response; two of the reported infants had cerebral hemorrhages ${ }^{2}$. All reported cases were extremely low birth weight premature infants. Contrarily to older children and adults, cerebral abscesses only rarely present in neonates with focal neurological signs. Furthermore, CSF analysis is frequently normal or non-contributory and screening with US rarely yields results that strongly suggest a cerebral abscess; sonography findings usually do not allow perfect distinction between the site of a previous hemorrhage and an abscess. Considering that germinal matrix hemorrhages are far more common than abscesses in pre-term infants, only a high degree of suspicion will allow accurate diagnosis ${ }^{5,7,8}$. The protocol for cerebral imaging in our nursery after this particular case and review has been to utilize US as a screening method; any findings in an infected neonate leads to a CT scan of the brain with intravenous contrast. Aggressive diagnostic measures are justified given the frequently poor neurological outcome of S. marcescens abcesses (Table).

Critical review of reported cases reveals an unsatisfactory neurological prognosis, with only 2 infants attaining good neurological development. The only consensus regarding treatment measures is that the enforcement of infection control measures after the isolation of S. marcescens in a NICU is essential to avoid generalized colonization and new sepsis cases. Optimal antibiotic therapy for S. marcescens CNS infections remains a controversial issue, complicated by rapidly developing in vivo resistance in spite of in vitro sensibility, due to an inducible cephalosporinase ${ }^{2}$. Initial antibiotic coverage with ampicillin and gentamicin or cefotaxime for $S$. marcescens sepsis frequently does not avoid CNS spread, as in our case ${ }^{2,7}$. We thus agree with Berger et al. that a deteriorating septic infant prompts the alteration of the antibiotic regimen, even though in vitro assays may reveal adequate sensibility, to a $3^{\text {rd }}$ or $4^{\text {th }}$ generation cephalosporin or meropenem plus amikacin in dosages appropriate for CNS penetration. In the specific case of a cerebral abscess, antibiotic therapy should be maintained for at least 6 to 8 weeks $^{2,9}$. Neurosurgical consultation must always be obtained, including abscess drainage when possible. Agent isolation in this unusual complication is desired since a longterm, aggressive antibiotic regimen will be utilized if $S$. marcescens is revealed. Furthermore, bacterial load reduction has already been proven elsewhere an important adjuvant to antibiotic therapy if abscesses are larger than $2 \mathrm{~cm}$ in diameter ${ }^{9}$

Diagnosis and treatment of this infrequent condi- 
tion is a challenge for any neonatologist. The poor survival rates of $S$. marcescens sepsis and the sequelae associated with CNS involvement should always prompt the use of aggressive diagnostic methods and antibiotic therapy. Ultimately, perhaps the most costeffective measure may be the enforcement of strict infection control protocols whenever S. marcescens colonization is discovered in a NICU, in order to prevent and rapidly treat the initial step of this rapidly deteriorating cascade, i.e., sepsis.

\section{REFERENCES}

1. Ragazzini F, La Cauza C, Ferrucci M. Infection by Serratia marcescens in premature children. Ann Paediatr 1965;205:289-300.

2. Berger A, Rohrmeister K, Haiden N, Assadian O, Kretzer V, Kohlhauser C. Serratia marcescens in the neonatal intensive care unit: re-em- phasis of the potentially devastating sequelae. Wien Klin Wochenschr 2002;114:1017-1022.

3. Campbell JR, Zaccaria E, Mason EO Jr, Baker CJ. Epidemiological analysis defining concurrent outbreaks of Serratia marcescens and methicillin-resistant Staphylococcus aureus in a neonatal intensive-care unit. Infect Control Hosp Epidemiol 1998;19:924-928.

4. Al-Harthi AA, Dagriri KA, Asindi AA, Bello CS. Neonatal meningitis. Saudi Med J 2000;21:550-553.

5. Ries M, Deeg KH, Heininger U, Stehr K. Brain abscesses in neonates: report of three cases. Eur J Pediatr 1993;152:745-746.

6. Kimpen JL, Brus F, Arends JP, de Vries-Hospers HG. Successful medical treatment of multiple Serratia marcescens brain abscesses in a neonate. Eur J Pediatr 1996;155:916.

7. Nagle RC, Taekman MS, Shallat RF, Cohen RA. Brain abscess aspiration in nursery with ultrasound guidance: case report. J Neurosurg 1986;65:557-559.

8. Lam AH, Berry A, Silva M, Williams G. Intracranial Serratia infection in preterm newborn infants. AJNR 1984;5:447-451.

9. Mamelak AN, Mampalam TJ, Obana WG, Rosenblum ML. Improved management of brain abscesses: a combined surgical and medical approach. Neurosurgery 1995;36:76-85. 